\title{
A NOÇÃo BOURDIEUSIANA DE HEXIS CORPORAL EM TESES E DISSERTAÇÕES BRASILEIRAS
}

\author{
LA NOCIÓN BOURDIEUSIANA DE HEXIS CORPORAL \\ EN LAS TESIS Y DISERTACIONES BRASILEÑNA
}

\section{THE BOURDIEUSIAN NOTION OF BODY HEXIS IN BRAZILIAN THESIS AND DISSERTATIONS}

\author{
Darbi Masson SUFICIER* \\ Alexandre Aparecido dos SANTOS* \\ Mateus Tobias VIEIRA ${ }^{\text {t*t }}$ \\ Luci Regina MUZZETI ${ }^{* * * *}$
}

RESUMO: O artigo apresenta a noção de hexis corporal na obra de Bourdieu e um levantamento de sua utilização em teses e dissertações brasileiras. A noção de hexis corporal compreende as disposições corporais do habitus, trata-se da compreensão do corpo enquanto um signum social. A busca realizada no Catálogo de Teses e Dissertações da CAPES revelou a utilização da noção de hexis corporal em

\footnotetext{
Universidade Federal de Mato Grosso do Sul. Campus Paranaíba - (UFMS), Paranaíba - MS - Brasil. ORCID: https://orcid.org/0000-0002-8476-9559. E-mail: darbi.suficier@ufms.br.

** Universidade Estadual Paulista - (UNESP), Araraquara - SP - Brasil. Doutorando (CAPES-DS) no Programa de Pós-Graduação em Ciências Sociais. ORCID: https://orcid.org/0000-0001-5901-8262. E-mail: alexandre.sociais@hotmail.com.

** Universidade Estadual Paulista - (UNESP), Araraquara - SP - Brasil. Doutorando (CAPES-DS) no Programa de Pós-Graduação em Ciências Sociais e membro do Núcleo de Estudos e Pesquisa sobre Emoções, Sociedade, Poder, Organização e Mercado (NESPOM). ORCID: https://orcid.org/0000-00026558-8779. E-mail: mateus.tobias@unesp.br.

**** Universidade Estadual Paulista - (UNESP), Araraquara - SP - Brasil. Departamento de Educação. Programa de Pós-Graduação em Educação Escolar. Programa de Pós-Graduação em Educação Sexual. ORCID: https://orcid.org/0000-0002-6808-2490. E-mail: luci.muzzeti@unesp.br.
} 
pesquisas empíricas com diversos grupos sociais, tais como: professores, militares, camponeses, esportistas, dentre outros. Nessas pesquisas, a noção é associada às análises que remetem a outros aspectos da obra de Bourdieu: a distinção social, o senso prático, as disputas simbólicas, as matrizes de classificações sociais e ao corpo socialmente tratado.

PALAVRAS-CHAVE: Hexis corporal. Habitus. Pierre Bourdieu. Catálogo de Teses \& Dissertações da CAPES.

RESUMEN: El artículo presenta la noción de hexis corporal en la obra de Bourdieu y una revisión de su uso en tesis y disertaciones brasileñas. La noción de hexis corporal comprende las disposiciones corporales del habitus, se trata de entender el cuerpo como signum social. La búsqueda realizada en el Catálogo de Tesis y Disertaciones de CAPES reveló el uso de la noción de hexis corporal en investigaciones empíricas con varios grupos sociales, como: profesores, militares, campesinos, deportistas, entre otros. En estas investigaciones, la noción se asocia a los análisis que hacen referencia a otros aspectos de la obra de Bourdieu: la distinción social, el sentido práctico, las disputas simbólicas, las matrices de clasificaciones sociales y el cuerpo socialmente tratado.

PALABRAS CLAVE: Hexis corporal. Habitus. Pierre Bourdieu. Catálogo de Tesis y Disertaciones de CAPES.

ABSTRACT: The article presents the notion of body hexis in Bourdieu's work and a review of its use in Brazilian theses and dissertations. The notion of body hexis comprehends the body dispositions of habitus, it is the understanding of the body as a social signum. The search made in the Catalogue of Thesis and Dissertations of CAPES revealed the use of the notion of body hexis in empirical researches with several social groups, such as: teachers, military, peasants, sportspeople, among others. In these researches, the notion is associated to the analyses which lead to other aspects of Bourdieu's work: the social distinction, the practical sense, the symbolic disputes, the matrices of social classifications and to the socially treated body.

KEYWORDS: Body hexis. Habitus. Pierre Bourdieu. CAPES Catalogue of Theses $\&$ Dissertations. 


\section{Introdução}

O artigo analisa a noção de hexis corporal, instância do habitus, na obra de Pierre Bourdieu e sua utilização em pesquisas empíricas disponíveis no Catálogo de Teses e Dissertações da CAPES.

O conceito de habitus, enquanto sistema de disposições duráveis, tal qual formulado por Bourdieu (2002, 2013a), é amplamente utilizado na interpretação da realidade social, assim como recebe diversas interpretações e críticas (SETTON, 2002; LAHIRE, 2003; WACQUANT, 2017). Entretanto, como destaca Peters (2009, p.4), existe uma "distinção, frequentemente ignorada pelos comentadores da obra de Bourdieu, entre os componentes cognitivo (eidos), normativo (ethos) e corpóreo-afetivo (hexis) do habitus". Por sua vez, Medeiros (2011, p.288) ressalta que Bourdieu: "[...] passa a referir-se às disposições em seus variados aspectos somente como habitus e não mais destacando hexis, ethos ou eidos, para evitar que se pudesse pensar de modo compartimentalizado, reforçando assim a noção de um sistema de disposições que tudo abrange". Dessa forma, depreende-se que Bourdieu (2007b) utiliza separadamente as diferentes instâncias do habitus (hexis, ethos e eidos) de forma pontual, pois estão implícitas no conceito tal qual a indissociabilidade da tríade conceitual: habitus - campo - capital.

A utilização dos elementos do habitus de maneira separada possui utilidade heurística desde que se leve em conta que são dimensões de um mesmo fenômeno e que operam juntos em uma articulação que os torna indissociáveis entre si (PETERS, 2010), uma vez que "na maior parte dos contextos sociopráticos onde atuamos, mente e corpo devem ser pensados ao longo de um único continuum, qual seja, o fluxo da atividade prática" (PETERS, 2010, p.28).

O conceito de habitus tem sua origem ligada a tradição filosófica aristotélica e pode ser encontrado no pensamento de vários autores ao longo do tempo (BOURDIEU, 2007b; WACQUANT, 2007; 2017). Porém, o uso e o sentido - tendo em vista aqui a construção e a aplicação do conceito - atribuídos ao habitus na obra de Bourdieu (2007b, p.76), fazem dele o construto teórico nodal do conhecimento praxiológico, em que é destacado "a dialética da interioridade e da exterioridade, isto é, da interiorização da exterioridade e da exteriorização da interioridade" (BOURDIEU, 2013a, p.53). Sobre o modo de conhecimento praxiológico, Sapiro (2017, p.127) afirma: "exige que se relacione o ponto de vista dos indivíduos, assim como suas crenças, com suas condições econômicas e sociais". Nesse sentido, habitus é o conceito mediador das instâncias individual e social, posto que é, para Bourdieu (1983):

[...] um produto dos condicionamentos que tende a reproduzir a lógica objetiva dos condicionamentos mas fazendo-a sofrer uma transformação; é uma espécie de 


\section{Darbi Masson Suficier, Alexandre Aparecido dos Santos, Mateus Tobias Vieira e Luci Regina Muzzeti}

máquina transformadora que faz com que "reproduzamos" as condições sociais da nossa própria produção, mas de uma maneira relativamente imprevisível, de uma maneira tal que não podemos passar simples e mecanicamente do conhecimento das condições de produção ao conhecimento dos produtos (BOURDIEU, 1983, p.140).

Em outro momento, Bourdieu (1999, p.64) define habitus como "lei social incorporada", resultado do processo de inscrição do mundo social na natureza biológica do agente (BOURDIEU, 1999, p.64), isto é, a "interiorização da exterioridade" (BOURDIEU, 2013a, p.53). Montagner (2006, p.519) sintetiza que: "Bourdieu debita esse trabalho de interiorização de uma hexis corporal à instância da educação primária, realizada primordialmente pela família e grupo social". Em outro momento, Bourdieu (2004, p.82) aponta “o habitus como social inscrito no corpo". Dessa forma, tem-se que o habitus é um conceito que visa "transcender a oposição entre objetivismo e subjetivismo: habitus é uma noção mediadora que ajuda a abolir a dualidade de senso comum entre o individual e o social" (WACQUANT, 2004, p.318, tradução nossa) $)^{1}$, essa mediação acontece ressaltando o modo como a sociedade é incorporada pelo indivíduo, na forma de disposições duráveis (WACQUANT, 2004).

\section{Habitus e hexis}

Habitus é o conceito central no pensamento de Bourdieu (BOLTANSKI, 2005), pois é por meio dele que o autor constrói a dinâmica de sua teoria (COSTA, 2007; CORCUFF, 2005). E, por ser um conceito nodal, é comum o uso de definições rígidas e imutáveis em trabalhos produzidos a partir dessa teoria. Sobre essa leitura de sua obra, Bourdieu (2007b, p.79) afirma: "Basta distender esses traços até o limite extremo, apresentando o habitus como uma espécie de princípio monolítico [...]". Uma das citações, recorrentes, utilizadas pelos pesquisadores como definição conceitual de habitus é:

As estruturas constitutivas de um tipo particular (as condições materiais de existência características de uma condição de classe), que podem ser apreendidas empiricamente sob a forma de regularidades associadas a um meio socialmente estruturado, produzem habitus, sistemas de disposições duráveis, estruturas estruturadas predispostas a funcionar como estruturas estruturantes, isto é, como princípio gerador e estruturador das práticas e das representações que podem

\footnotetext{
1 No original: habitus is a mediating notion that helps us revoke the commonsense duality between the individual and the social. (WACQUANT, Löic. Habitus. In: BECKERT, Jens; ZAFIROVSKI, Milan (Ed.). International Encyclopedia of Economic Sociology. Londres: Routledge, 2004, p. 318).
} 
ser objetivamente adaptadas a seu fim sem supor a intenção consciente dos fins e o domínio expresso das operações necessárias para atingi-los e coletivamente orquestradas, sem ser o produto da ação organizadora de um regente. (BOURDIEU, 2013a, p.53-4).

Entretanto, pontua-se que, apesar de suas utilizações monolíticas, o conceito de habitus foi progressivamente construído na obra de Bourdieu. Em uma das primeiras vezes em que a noção de hexis corporal é observada (BOURDIEU, 2006), pode-se vislumbrar esse processo de construção do conceito de habitus e seus ressignificados na trajetória intelectual do autor. Em sua pesquisa sobre os camponeses da região do Béarn, Bourdieu (2006, p.85) diz que: “A propósito, é preciso admitir que as técnicas corporais constituem verdadeiros sistemas, solidários a todo um contexto cultural. Aqui não é o caso de analisar os hábitos motores característicos do camponês de Béarn, esse habitus que denuncia o paysanás, o camponês pesadão".

Bourdieu (2006, p.85) demonstra que: "A observação popular apreende perfeitamente essa hexis [do camponês], que serve de fundamento aos estereótipos". Evidencia-se que os conceitos estavam em construção, com a utilização de disposições corporais ligadas à motricidade do camponês referidas como habitus. Conforme explica Boltanski (2005, p.161-2): "O conceito de habitus, que aparece na obra de Pierre Bourdieu desde o início dos anos 1960, será, como todo mundo sabe, objeto de amplos desenvolvimentos ulteriores e tomará lugar no centro do campo conceitual bourdieusiano". Dessa forma, Bourdieu (2006, p.85) pontua que: “[...] o habitus corporal consiste naquilo que se vive como mais natural, aquilo sobre o que a ação consciente não tem controle"; e adiante: "De fato, hexis corporal é antes de tudo, signum social".

Percebe-se que, nessa imbricação entre as noções que compõem o habitus (ethos, hexis, eidos), a hexis constitui a dimensão relativa ao aprendizado e internalização de um conjunto de maneiras de se relacionar com o próprio corpo. Maneiras socialmente localizadas e que possuem a capacidade de classificar o indivíduo na estrutura do grupo e que, por outro lado, são percebidas como naturais (PETERS, 2010), como se nota na construção da hexis que define o masculino e o feminino (BOURDIEU, 1999).

Seus primeiros trabalhos (2007c [1958], 2006 [1962]) em pesquisas etnológicas de inspiração estruturalistas culminaram em sua teoria da prática (BOURDIEU, 2002, 2007b, 2009). Essa aproximação a uma abordagem antropológica, ressalta o emprego por Bourdieu (2006, p.85-6) da noção de técnica corporal, desenvolvida por Mauss (1984):

Digo expressamente as técnicas corporais porque é possível fazer a teoria da técnica corporal a partir de um estudo de uma exposição, de uma descrição pura 


\section{Darbi Masson Suficier, Alexandre Aparecido dos Santos, Mateus Tobias Vieira e Luci Regina Muzzeti}

e simples das técnicas corporais. Entendo por essa palavra as maneiras como os homens, sociedade por sociedade e de maneira tradicional, sabem servir-se de seus corpos. Em todo caso, é preciso proceder do concreto ao abstrato, e não inversamente. (MAUSS, 1984, p.211).

Bourdieu (2006, 2007c) constrói seu trabalho de campo de forma muito próxima a uma etnografia antropológica, uma vez que justifica a metodologia de observação por ele empregada da seguinte forma: "Eis por que, em vez de esboçar uma análise metódica das técnicas corporais, pareceu preferível registrar a imagem que os moradores da cidade fazem do camponês e que, para o bem ou para o mal, ele tende a introjetar" (BOURDIEU, 2006, p.86). Mauss (1984, p.216), em seu trabalho sobre as técnicas corporais, alertava que "a noção de educação podia sobrepor-se à noção de imitação". Com isso, o autor dá uma maior margem de manobra ao indivíduo, ou seja, maior autonomia em detrimento dos efeitos da reprodução social realizada por meio da repetição. Segundo aponta Rosa (2019, p.345): “A análise de Mauss [...] rompe com a visão biológica do corpo, colocando em evidência a dimensão social e cultural, através da definição que ele dá às técnicas do corpo". Diz Mauss (1984):

Tive pois, durante numerosos anos, esta noção da natureza social do "habitus". Peço que observem que digo em bom latim, compreendido na França, "habitus". A palavra traduz, infinitamente melhor que "hábito", o "exigido", o "adquirido" e a "faculdade" de Aristóteles (que era um psicólogo). Ele não designa esses hábitos metafísicos, esta "memória" misteriosa, tema de volumes ou de curtas e famosas teses. Esses "hábitos" variam não simplesmente com os indivíduos e suas imitações, mas, sobretudo, com as sociedades, as educações, as conveniências e as modas, com os prestígios. É preciso ver técnicas e a obra da razão prática coletiva e individual, ali onde de ordinário veem-se apenas a alma e suas faculdades de repetição. (MAUSS, 1984, p.214).

Essa ligação entre o desenvolvimento da noção de hexis corporal e a utilização, em um primeiro momento, da noção de técnicas corporais de Mauss por Bourdieu, deve ser compreendida pela importância atribuída à construção social do corpo. Para Bourdieu (2013b, p.38): "a prática poderia ser definida como o resultado do aparecimento de um habitus, sinal incorporado de uma trajetória social", ou seja, no corpo e - em seus mais diversos usos - vislumbra-se, empiricamente, o construto teórico do habitus.

Conforme demonstram Wacquant $(2007 ; 2017)$ e Galak (2009), ao retomarem os diversos significados do conceito de habitus e sua utilização ao longo do tempo (Durkheim, Weber, Elias, etc.), "as raízes do habitus encontram-se na noção aris- 
totélica de hexis, elaborada na sua doutrina sobre a virtude" (WACQUANT, 2007, p.25). Assim, a palavra habitus, do verbo latino habere (ter, possuir), é uma tradução do grego hexis, hábito permanente (AMOSSY, 2005), no sentido de disposição (HOBUSS, 2010, p.224).

Bourdieu propôs, como demonstra Amossy (2005, p.26), "uma reinterpretação da noção de ethos no quadro do conceito de habitus". Ou seja, deu um novo sentido para as palavras-conceito habitus e hexis, incorporando ao primeiro outra noção clássica, o ethos. Assim, em Bourdieu, habitus deixa de ser uma reinterpretação do grego hexis e passa a incorporar duas noções com novos significados: hexis corporal e ethos.

Segundo Amossy (2005), o ethos em Aristóteles refere-se à imagem de si construída pelo orador diante de sua plateia. Conforme a autora expõe, o ethos será utilizado de diversas formas ao longo do tempo, mas sempre mantendo como um dos pilares do seu significado a noção de imagem de si. Bourdieu (1983, p.138-9) dá um novo significado ao ethos, utilizando-o para "designar um conjunto objetivamente sistemático de disposições de dimensão ética, de princípios práticos (sendo a ética um sistema intencionalmente coerente de princípios explícitos".

Amossy (2005, p.26) sintetiza as diferenças entre ethos e hexis corporal em Bourdieu: "Como componente do habitus, o ethos designa em Bourdieu um conjunto de princípios interiorizados que guiam nossa conduta de forma inconsciente; a hexis corporal refere-se a posturas, as relações com o corpo, igualmente interiorizadas"; ou, de forma sintética: "O corpo está no mundo social, mas o mundo social está no corpo" (BOURDIEU, 2007b, p.185); ou, em outras palavras, "a força do ethos é que se trata de uma moral que se tornou hexis, gesto, postura" (BOURDIEU, 1983, p.104).

A importância da instância corporal para a construção do conceito de habitus é destacada por Durand (2017):

No conjunto de suas pesquisas de campo, Bourdieu procura mostrar, sempre que possível, indivíduos de corpo inteiro, pois é na hexis corporelle que se inscrevem melhor as determinações sociais. Reações, gestos, posturas, modos de falar, de andar, de se alimentar, de se limpar, tudo operando de modo prático, constituem um imenso mapa que muito diz da origem de classe, da inserção familiar, da identidade de gênero, da posição social passada e presente e do momento no ciclo da vida. (DURAND, 2017, p.74-5)

Além de a hexis corporal ser a instância do habitus que faz com que o agente seja seu próprio signum social, isto é, aquilo que será visto pelo outro, sua postura, sua linguagem, suas roupas, também compreende a incorporação da visão do outro sobre si. Compreende-se que, como signum social (BOURDIEU, 2006), o corpo 


\section{Darbi Masson Suficier, Alexandre Aparecido dos Santos, Mateus Tobias Vieira e Luci Regina Muzzeti}

desvela o processo de "exteriorização da interioridade" (BOURDIEU, 2013a, p.53). De acordo com Bourdieu (2007a):

Dimensão fundamental do sentido da orientação social, a hexis corporal é uma maneira prática de experimentar e exprimir o sentido que se tem, como se diz, de seu próprio valor social: a relação que se mantém com o mundo social e o lugar que a pessoa se atribui nesse mundo nunca se declara tão bem quanto através do espaço e do tempo que ela se sente no direito de tomar aos outros, e, mais precisamente, o lugar que ocupa com seu corpo no espaço físico, por uma postura e por gestos firmes ou reservados, amplos ou acanhados (de alguém que pretenda parecer importante diz-se, de forma bem clara, que é "espaçoso") e com sua fala no tempo, pela parte do tempo de interação de que se apropria e pela maneira, segura ou agressiva, desenvolta ou inconsciente, de se apropriar desse tempo. (BOURDIEU, 2007a, p.439-40)

Da relação corpo - hexis, tem-se que:

O hexis corporal, no qual entram, ao mesmo tempo, a conformação propriamente física do corpo (o "físico") e a maneira se servir dele, a postura, a atitude, ao que se crê expressa o "ser profundo", a "natureza" da "pessoa" em sua verdade, segundo o postulado da correspondência entre o "físico" e o "moral", nascido do conhecimento prático ou racionalizado que permite associar propriedades "psicológicas" e "morais" a traços corporais ou fisiognomônicos (um corpo delgado e esbelto, por exemplo, percebido como sinal de um controle viril de apetites corporais) (BOURDIEU, 1999, p.80).

Neste sentido, o corpo é compreendido como o elo entre o individual e o social, na medida em que expressa o habitus de cada agente. Assim, as maneiras de falar, de se vestir ou de se portar à mesa atuam como marcadores da origem social do corpo, como tem-se no exemplo utilizado por Bourdieu, em que as práticas corporais qualificam o pertencimento a um grupo:

Sua própria hexis corporal [do pequeno-burguês], na qual se exprime toda a sua relação objetiva com o mundo social, é a de um homem que deve fazer-se pequeno para passar pela porta estreita que dá acesso à burguesia: por obrigar-se a ser estrito e sóbrio, discreto e severo, em sua maneira não só de vestir, mas também de falar - essa linguagem hipercorreta pelo excesso de vigilância e prudência -, em seus gestos e em toda a sua postura, falta-lhe sempre um pouco de envergadura, amplidão, largueza e liberalidade. (BOURDIEU, 2012, p.108). 
No mesmo sentido, Bourdieu (2007b, p.172) assinala que: "Aprendemos pelo corpo. A ordem social se inscreve nos corpos por meio dessa confrontação permanente, mais ou menos dramática, mas que sempre confere um lugar importante à afetividade e, mais ainda, às transações afetivas com o ambiente social".

Por essa perspectiva, em uma sociedade estruturada por disputas por poder e prestígio, que definem e são definidas por uma classe dominante, tem-se que o corpo em si - enquanto expressão de uma hexis corporal que a todo o tempo evidencia um signo de pertencimento e de origem social - é um grande marcador das distinções e das diferenças entre as classes sociais (BOURDIEU, 1999, 2007b). Dessa forma, enquanto portador de um signo de origem social, o próprio corpo torna-se uma expressão prática que pode ser legitimada ou não no espaço social pelo qual circula, assim estando diretamente ligado às relações de julgamento sobre o seu pertencimento social:

Não há dúvida de que os julgamentos que pretendem aplicar-se à pessoa em seu todo levam em conta não somente a aparência física propriamente dita, que é sempre socialmente marcada (através de índices como corpulência, cor, forma do rosto), mas também o corpo socialmente tratado (com a roupa, os adereços, a cosmética e principalmente as maneiras e a conduta) que é percebido através de taxonomias socialmente constituídas, portando lido como sinal da qualidade e do valor da pessoa. (BOURDIEU; SAINT- MARTIN, 2012, p.193).

Ao relacionar a hexis corporal com as taxonomias sociais, Bourdieu e SaintMartin (2012) discorrem que a aparência física pode estar ou não em conformidade com a hexis corporal. Nesse sentido, todo o corpo é continuamente objeto de classificação, pois:

A representação social do próprio corpo, com que cada agente social deve contare isso desde sua origem - para elaborar sua representação subjetiva de seu corpo (e, mais profundamente, de sua hexis corporal), é obtida, assim, pela aplicação de um sistema de classificação social, cujo princípio é o mesmo dos produtos sociais aos quais tal sistema se aplica (BOURDIEU, 2014, p.249).

Assim, o corpo seria um objeto classificatório, uma vez que: “A hexis corporal corresponde às posturas, disposições do corpo, relações ao corpo, interiorizadas inconscientemente pelo indivíduo ao longo de sua história" (BONNEWITZ, 2003, p.77); trata-se também de um símbolo dinâmico de distinção social que carrega em si registros morais que caracterizam sua origem social e todo o percurso de sua formação, posto que: 


\section{Darbi Masson Suficier, Alexandre Aparecido dos Santos, Mateus Tobias Vieira e Luci Regina Muzzeti}

[...] hexis corporal fornece o sistema de índices através dos quais é reconhecida-irreconhecida uma origem de classe: "fina distinção", "um poeta", "qualidades originais e parcialmente dissimuladas por uma timidez comunicativa", "espírito sombrio e sensível"; assim, como a enumeração das virtudes que são atribuídas a tal outra ("capacidade de trabalho", "atividade científica variada e fecunda", "devotamento", "grande honestidade intelectual", "atividade prodigiosa e discreta", "robusto, trabalhador, sorridente e bom") não é nada mais que uma longa paráfrase das notações esparsas onde seu hexis é evocado: "uma saúde de ferro dentro de um corpo atlético", "vigoroso fanfarrão" (BOURDIEU; SAINTMARTIN, 2012, p.193-4).

Portanto, pensar o conceito bourdiesiano de habitus em sua perspectiva antropológica (WACQUANT, 2006), por meio das questões próprias à hexis corporal (BOURDIEU, 2006), é remeter a noção de corpo dentro das disputas simbólicas que configuram e estruturam o contexto de sua origem social. Tal condição permite entender que no conceito de habtus: "A hexis corporal é a mitologia política realizada, incorporada, tornada disposição permanente, maneira durável de se portar, de falar, de andar, e, dessa maneira, de sentir e de pensar" (BOURDIEU, 2009, p.114).

O corpo como símbolo distintivo é um objeto que comunica, ou seja, que remete por si só a questões de pertencimento ou de recusa social. Segundo Bourdieu (2009, p.121): “A hexis corporal fala imediatamente à motricidade, como esquema postural que é ao mesmo tempo singular e sistemático, porque solidário de todo um sistema de objetos e carregado de uma massa de significações e de valores sociais". Ou, conforme aponta Medeiros (2011, p.285): “O corpo passa a ser portador do habitus uma vez que as disposições incorporadas moldam o corpo a partir das condições materiais e culturais, até torná-lo um corpo social".

Enquanto objeto comunicante, o corpo pode ser entendido dentro de um sistema de economia simbólica, visto que os códigos inscritos nele são reconhecidos por corpos que também carregam estes símbolos de pertencimento. Um exemplo dessa relação no cotidiano pode ser dado pelos jogos de linguagem ou pelas disputas discursivas, ou seja, relações de disputa entre corpos que apresentam e reconhecem os mesmos códigos simbólicos (BOURDIEU, 2004; 2007b).

Essa dinâmica de reconhecimento e pertencimento, que é muito particular as disputas simbólicas, só é possível porque:

A linguagem é uma técnica do corpo e a competência propriamente linguística (especialmente a fonologia) uma dimensão da hexis corporal na qual se exprime toda relação com o mundo social. A hexis corporal, uma característica de uma classe, submete o aspecto fonológico do discurso a uma deformação sistemática. (BOURDIEU, 2013c, p.165). 
Ao direcionar o olhar para as disputas discursivas tem-se como objetivo destacar o próprio corpo enquanto discurso, enquanto um bem simbólico que é constantemente interpretado e classificado nos mais distintos contextos sociais.

Essa classificação e interpretação de pertencimento e origem social por intermédio do corpo é muitas vezes realizada pelo próprio agente que, mesmo sem saber o porquê, opta por estar e frequentar alguns tipos de ambientes em detrimento de outros. Tal condição remete ao fato de que "o corpo não representa um papel, não interpreta um personagem, e sim se identifica com este formato determinado socialmente, constituindo a partir deste formato a imagem de si" (MEDEIROS, 2017, p.133). Dessa forma, a hexis corporal representa o social que se torna e que se faz corpo, posto que revela uma relação em que a cultura:

[...] é progressivamente incorporada e que dá ao corpo sua fisionomia propriamente social, é uma maneira global de portar seu corpo, de o apresentar aos outros, e exprime, entre outras coisas, uma relação particular - de concordância ou de discordância - entre o corpo real e o corpo legítimo (tal como ele se define por uma classe particular de esquemas de percepção) ou, se preferimos, uma antecipação inconsciente das chances de sucesso da interação que contribui para definir essas chances (pelos traços comumente descritos como segurança, confiança em si, etc.). (BOURDIEU, 2014, p.255).

Dentro desta perspectiva, a hexis corporal corresponde a esse processo de construção de uma imagem de si e de adequação aos contextos sociais determinados e possibilitados por uma origem social e por todas as experiências práticas acumuladas durante a trajetória de formação do agente. Assim, a hexis corporal é o signo mais palpável daquilo que Bourdieu (2013d) definiu enquanto habitus de classe ou individual.

\section{A utilização da noção de hexis corporal em pesquisas empíricas no Catálogo de Teses e Dissertações da CAPES}

Para exemplificar algumas possibilidades da utilização da noção de hexis corporal em pesquisas empíricas, realizou-se uma pesquisa documental em que a coleta de dados foi realizada no Catálogo de Teses e Dissertações da CAPES. Como critério de busca, utilizou-se a palavra hexis e a expressão "hexis corporal". Foram identificados 28 trabalhos com a palavra hexis e, dentre estes, 18 trabalhos com a expressão hexis corporal. Os 24 trabalhos disponibilizados na íntegra pela CAPES e pelos programas de pós-graduação foram analisados em sua totalidade. 


\section{Darbi Masson Suficier, Alexandre Aparecido dos Santos, Mateus Tobias Vieira e Luci Regina Muzzeti}

Desses trabalhos, 10 foram desconsiderados para esta pesquisa por: i) não utilizar a noção de hexis corporal como categoria analítica; ii) utilizar hexis no contexto da Filosofia. Além dos 14 trabalhos restantes (4 teses e 10 dissertações), incluiu-se a tese de Nummer (2010). As 15 pesquisas foram desenvolvidas em programas de pós-graduação nas áreas de Educação (6), Ciências Sociais (3), Enfermagem (2), Letras, Contabilidade, Ciências da Motricidade e Artes (1 cada).

Abaixo são destacados 9 desses trabalhos por meio de um recorte que objetivou apresentar possibilidades da utilização da noção de hexis corporal em diferentes grupos e contextos sociais. Os trabalhos podem ser agrupados em torno de cinco aspectos na utilização da noção: corpo socialmente tratado, senso prático, disputas simbólicas, matrizes sociais de classificação e distinção social.

O corpo socialmente tratado faz-se presente na pesquisa de Coury (2010), que analisa a hexis corporal de enfermeiras que atuaram no enfrentamento da gripe espanhola em 1918. A pesquisa faz uso de fotografias e de textos do período presentes em relatórios institucionais e na imprensa. Diz a autora:

Esse corpo legítimo é traduzido na hexis corporal, que é uma relação durável e generalizada com o corpo real, que foram analisados através da leitura da linguagem corporal e posição dos retratados no texto imagético, como, por exemplo, mãos juntas na altura da cintura, corpo deitado com os braços levantados, braços cruzados e posição da cabeça para o lado contrário da mira da lente da máquina fotográfica. (COURY, 2010, p.29).

A autora, "através da leitura da linguagem corporal e posição dos retratados no texto imagético" (COURY, 2010, p.29), contextualiza a imagem pública da enfermeira e sua relação com a atuação da Cruz Vermelha Brasileira.

As pesquisas de Matos (2019) e Nummer (2010) são marcadas pelo aspecto do senso prático. Matos (2019), em sua pesquisa junto a nove dançarinos e nove capoeiristas, utiliza-se da técnica de mapa cultural narrado, com a coleta de dados por meio de testemunhos e narrativas, os discursos coletados nos encontros com os grupos e um mapa corporal de tamanho natural. Dentre os resultados, pode-se ressaltar as diferenças entre os gêneros nas relações estabelecidas com o corpo:

Nesse sentido, a distinção entre o praticante e a "pesquisadora estranha às práticas" se inicia pela naturalização dessa linguagem, comum aos participantes e estranhas a mim. Em seguida, os corpos vão assimilando os novos movimentos e posições. A aquisição de posturas e movimentos que compõem a identidade de cada grupo faz a ponte entre o corpo, a hexis e o habitus, explico: é necessário conhecer os movimentos para ser capaz de desenvolver-se. (MATOS, 2019, p.120). 
A autora mostra que, entre dançarinos e capoeiristas, a hexis corporal "ganha visibilidade na realização dos movimentos, que possuem nomes próprios e fazem parte do vocabulário cotidiano dos grupos" (MATOS, 2019, p.118). Assim, a prática social feita corpo, a própria hexis corporal, independe de sua compreensão teórica, tal qual o senso prático de Bourdieu (2009).

Nummer (2010), também utilizando-se da noção de senso prático, realizou uma etnografia junto a um agrupamento da polícia militar com o objetivo de compreender o pertencimento à profissão e a relação com os estilos de vida e a agency. Pontualmente, a noção de hexis corporal é utilizada como categoria explicativa, como no trecho: "Sua hexis corporal foi adestrada no curso de formação, e a farda é um índice simbólico sem o qual muitos não conseguem mantê-la" (NUMMER, 2010, p.212). A autora destaca que:

Outra característica marcante já destacada é a hexis corporal, ou seja, mesmo sem a farda, entre os interlocutores desse grupo é comum a posição com os braços para trás ou apoiados no cinto da calça, como no "cinto da guarnição" quando fardados. Independentemente da situação social em que se encontram, mantém uma postura ereta tanto de pé quanto sentados e usam frequentemente os jargões policiais para conversar com colegas. (NUMMER, 2010, p.210).

No que concerne às disputas simbólicas, a pesquisa de Vlastuin (2013) analisa a trajetória do voleibol feminino no Brasil no período de 1980 a 2008. Os dados foram coletados por meio de entrevistas com agentes de diferentes gerações do esporte, o que possibilitou a percepção de disputas simbólicas em que os usos sociais do corpo passaram a ser um marcador simbólico significativo. Vlastuin (2013) ressalta que:

A garantia de que essas gerações não vivam para sempre prescreve mudanças contínuas em todas as gerações, já que a instância biológica faz com que as mesmas sejam substituídas continuamente, em prol da busca por corpos cada vez mais atléticos e "adequados" aos padrões culturais mutáveis das diferentes sociedades. No voleibol feminino, essas sucessões podem ser observadas pelas disputas de posições entre atletas e técnicos, na manutenção e rotatividade de equipes competitivas e na manutenção e/ou desistência de patrocínios das equipes no decorrer das temporadas. (VLASTUIN (2013, p.65).

A autora faz uso do corpus conceitual de Bourdieu para analisar a trajetória social de cinco atletas profissionais que participaram dos Jogos Olímpicos desse período. A noção de hexis corporal é utilizada como um complemento ao conceito de habitus para compreender, entre outros aspectos, o aumento da visibilidade do 


\section{Darbi Masson Suficier, Alexandre Aparecido dos Santos, Mateus Tobias Vieira e Luci Regina Muzzeti}

esporte: “As 'Musas do Vôlei' constituem exemplos de como o corpo das jogadoras, aliado a um grande potencial técnico e tático, marcaram os anos de 1980 na modalidade" (VLASTUIN, 2013, p.55).

As pesquisas de Oliveira (2017) e Schneider (2006) utilizam a noção de hexis sob o prisma das matrizes sociais de classificação. A pesquisa de Oliveira (2017) fez uso da observação de um conselho de classes de uma escola de ensino fundamental para compreender o julgamento professoral. A noção de hexis corporal é utilizada como uma das categorias em que foram sistematizados os dados coletados, com destaque para as adjetivações proferidas pelos professores em relação a seus alunos. Para a pesquisadora é:

[...] possível que, tanto para o grupo A quanto para o grupo B, o ingliding seja uma estratégia de mobilização/manutenção de capital econômico. Em outras palavras, fazer uso da variante ditongada é uma estratégia de distinção que, nesse caso, serve para que os agentes sociais se marquem como pessoas que ocupam posições relativamente superiores no espaço social. (OLIVEIRA, 2017, p.197).

Por sua vez, Schneider (2006) faz uso de um amplo conjunto de procedimentos metodológicos de coleta de dados junto a um grupo de alunos do oitavo ano do ensino fundamental e do primeiro ano do ensino médio: dinâmicas de grupo, atividades com desenho, fotografias, questionários e entrevistas. Isso possibilitou a autora a compreensão de algumas matrizes de classificações ligadas aos usos sociais do corpo operacionalizadas pelos alunos, como no exemplo a seguir: "O julgamento estudantil é estruturado a partir da nota e da atitude do estudante diante da escola, do aprender e também de seu hexis corporal. CDF, "cu de ferro", é uma expressão de hexis corporal simbólico, ou seja, uma disposição para suportar o cansaço exigido pelos estudos" (SCHNEIDER, 2006, p.82).

Nesse estudo, a noção de hexis corporal é utilizada como um componente analítico da "complexidade com que se entrelaçam as características físicas, intelectuais e morais na composição do julgamento estudantill" (SCHNEIDER, 2006, p.52).

Por fim, três pesquisas se utilizam da noção de hexis remetendo-se aos aspectos ligados à distinção social. Em $O$ corpo que dança: a história-social e hexis corporal no balé clássico, Souza (2009) analisa a construção social do corpo do bailarino clássico contemporâneo. Diz a autora:

Ao observar bem as posturas das bailarinas, percebemos que o julgamento do que é e foi considerado delicado e belo não é o mesmo, o conceito do que é ter postura de uma bailarina legitimada também sofreu mutação. A economia dos gestos opera aqui como instrumento de uma racionalidade que a todo o momento impõe superação com a finalidade de demonstrar distinção (SOUZA, 2009, p.40). 
Por meio de categorias como métrica, movimento, perspectiva e autocontrole e do conceito de habitus, são apontadas as contradições presentes na relação entre a hexis corporal exigida do bailarino - de distinção social - e aquela advinda, em muitos casos, de outra origem social. Além da pesquisa histórica e sociológica sobre o balé contemporâneo, a autora realizou entrevistas com um professor de dança e um diretor de grupo.

Em "De mal com o espelho": um estudo sobre a (re)configuração de corpos femininos pela cirurgia plástica, Garcia (2013) entrevista, de forma individual e coletiva, um grupo de seis mulheres que realizaram procedimentos cirúrgicos com finalidade estética. Garcia (2013) aponta:

Se considerarmos a origem tradicional dessas mulheres, vinculada a um ethos interiorano que preserva valores tradicionais, podemos entender o processo de (re)configuração, conformação, da hexis corporal como uma tentativa de modernização de si, visto que a própria concepção de mulher poderosa advém de certo modelo identitário de mulher moderna, presente sobretudo nas grandes cidades. O modelo de mulher poderosa - mulher independente e sedutora - relaciona-se diretamente ao modelo trazido ao Brasil por referências de um estilo de vida estrangeiro (norte-americano), veiculado, por exemplo, pela revista Nova/ Cosmopolitan: a mulher cosmopolita, a mulher "nova". (GARCIA, 2013, p.65).

O grupo, autodenominado de 'poderosas', é “marcado pela preocupação constante com questões relativas à saúde e à boa forma corporal" (GARCIA, 2013, p.38). Para a autora, o grupo exprime um gosto de classe - enquanto um princípio classificatório incorporado - ao se opor àquilo que classifica como vulgar.

A pesquisa de Oliveira (2018) se utiliza da noção de hexis corporal como um dos componentes da investigação sobre os aspectos da variação linguística do português falado na cidade de Porto Alegre. Os dados foram coletados mediante a utilização de procedimentos etnográficos e de um conjunto de vinte e quatro entrevistas.

O autor aponta para a relação de classificação e, assim, de distinção existente entre aspectos da fala, das vestimentas e do contexto social dos participantes:

Nessa classificação, indicadores são variáveis que não estão sujeitas à variação em relação à formalidade de fala e têm pouca força avaliativa, constituindo-se como traços linguísticos encaixados numa matriz social. Marcadores, diferentemente, exibem tanto estratificação em relação à formalidade de fala quanto estratificação social. Seu uso pode se dar de maneira inconsciente, de forma que seus usuários não apresentam discurso metalinguístico acerca do uso e do julgamento 


\section{Darbi Masson Suficier, Alexandre Aparecido dos Santos, Mateus Tobias Vieira e Luci Regina Muzzeti}

das variantes, e seu julgamento social, apesar de inconsciente, produz respostas regulares em testes de percepção e avaliação subjetiva. (OLIVEIRA, 2018, p.29).

Conforme as pesquisas aqui apresentadas, a utilização da noção de hexis corporal possui aplicação diversificada e cada uma das pesquisas se volta para compreensão de diferentes fenômenos sociológicos. Ao considerar a articulação entre os vários elementos do habitus, essas pesquisas priorizam a observação de aspectos corporais e motores na construção do objeto.

\section{Considerações finais}

Ao longo deste artigo são apresentados alguns recortes da utilização da noção de hexis corporal na construção do conceito bourdieusiano de habitus. Para isso, retomou-se a construção do conceito por Bourdieu (2002, 2006, 2013a) e as especificidades da hexis corporal na moldagem, interiorização e aprendizagem, inconsciente e perene de modos de dispor o próprio corpo. Nesse sentido, a hexis corporal é a expressão da inscrição do mundo social na natureza biológica do agente (Bourdieu, 1999, p.64). Assim, a hexis corporal, enquanto signum social, sinaliza para "o habitus como social inscrito no corpo" (BOURDIEU, 2004, p.82) ou, de forma empírica, para o processo de interiorização da exterioridade e exteriorização da interioridade (BOURDIEU, 2013a).

A ideia de um corpo feito símbolo, na medida em que suas práticas são elementos comunicantes dentro de uma relação de distinção social, pode elucidar as características e as possibilidades da noção de hexis corporal em abordagens teóricas que operacionalizam de alguma forma os conceitos de Bourdieu. Nessa linha, nos trabalhos aqui apresentados a noção de hexis aparece ligada à diferentes análises que remetem: a distinção social (SOUZA, 2009; GARCIA, 2013; OLIVEIRA, 2018), ao senso prático (MATOS, 2019; NUMMER, 2010), a disputas simbólicas (VLASTUIN, 2013), a matrizes de classificações sociais (OLIVEIRA, 2017; SCHNEIDER, 2006), ao corpo socialmente tratado (COURY, 2010), dentre outros.

Os trabalhos analisados permitem constatar a capacidade operacional do conceito de habitus e, especificamente, da noção de hexis corporal enquanto categoria explicativa, na medida em que demonstram, empiricamente, a internalização de estruturas exteriores e a externalização das interiores nas formas de modos de dispor do próprio corpo; e evidenciam em suas análises os critérios de hierarquização dos agentes em certo contexto através de cargas classificatórias que revelam, pelo uso do corpo no espaço, o pertencimento ou não do agente ao espaço social determinado.

A utilização do conceito de habitus demanda uma ancoragem empírica encontrada nas expressões da hexis corporal, uma vez que o corpo - e sua circulação pelos 
espaços sociais - pode ser entendido enquanto expressão prática em meio a um jogo de disputas por pertencimentos socialmente legitimados, dessa forma fundem-se as relações de julgamento sobre o pertencimento social. Por meio da hexis corporal o corpo se torna o próprio signum social (BOURDIEU, 2006), passível de ser lido e classificado enquanto "corpo socialmente tratado" (BOURDIEU; SAINT- MARTIN, 2012, p. 193).

\section{REFERÊNCIAS}

AMOSSY, Ruth. Da noção retórica de ethos à análise do discurso. In: AMOSSY, Ruth (org.). Imagens de si no discurso: a construção do ethos. São Paulo: Contexto, 2005.

BOLTANSKI, Luc. Usos fracos e usos intensos do habitus. In: ENCRÉVE, Pierre; LAGRAVE, Rose-Marie (Orgs.). Trabalhar com Bourdieu. Rio de Janeiro: Bertrand Brasil, 2005.

BONNEWITZ, Patrice. Primeiras lições sobre a sociologia de P. Bourdieu. Petrópolis: Vozes, 2003.

BOURDIEU, Pierre. Notas provisórias sobre a percepção social do corpo. Pro-Posições, Campinas, v. 25, n. 1, p.247-256, abr. 2014. Disponível em: http://www.scielo.br/scielo. php?script=sci_arttext\&pid=S0103-73072014000100014\&lng=en\&nrm=iso. Acesso em: 04 ago. 2020.

BOURDIEU, Pierre. Esboço de uma Teoria da Prática. In: ORTIZ, Renato (Org.). A Sociologia de Pierre Bourdieu. São Paulo: Olho d'Água, 2013a.

BOURDIEU, Pierre. Trabalhos e projeto. In: ORTIZ, Renato (Org.). A Sociologia de Pierre Bourdieu. São Paulo: Olho d'Água, 2013 b.

BOURDIEU, Pierre. A economia das trocas linguísticas. In: ORTIZ, Renato (Org.). A Sociologia de Pierre Bourdieu. São Paulo: Olho d'Água, 2013c.

BOURDIEU, Pierre. Gostos de classe e estilos de vida. In: ORTIZ, Renato (Org.). A Sociologia de Pierre Bourdieu. São Paulo: Olho d’Água, 2013d.

BOURDIEU, Pierre. Futuro de classe e causalidade do provável. In: NOGUEIRA, Maria Alice; CATANI, Afrânio (Orgs.). Escritos de Educação. Petrópolis: Vozes, 2012.

BOURDIEU, Pierre. O senso prático. Petrópolis: Vozes, 2009.

BOURDIEU, Pierre. A distinção: crítica social do julgamento. São Paulo: Edusp; Porto Alegre: Zouk, 2007a.

BOURDIEU, Pierre. Meditações Pascalianas. Rio de Janeiro: Bertrand Brasil, $2007 \mathrm{~b}$. 


\section{Darbi Masson Suficier, Alexandre Aparecido dos Santos, Mateus Tobias Vieira e Luci Regina Muzzeti}

BOURDIEU, Pierre. Antropología de Argelia. Madri: Editorial Universitaria Ramón Areces, 2007c.

BOURDIEU, Pierre. O camponês e seu corpo. Rev. Sociol. Polít., Curitiba, 26, p.83-92, jun. 2006. Disponível em: http://www.scielo.br/pdf/rsocp/n26/a07n26.pdf. Acesso em: 04 ago. 2020.

BOURDIEU, Pierre. Coisas ditas. São Paulo: Brasiliense, 2004.

BOURDIEU, Pierre. Esboço de uma teoria da prática - precedido de Três Estudos de Etnologia Cabila. Oeiras: Celta, 2002.

BOURDIEU, Pierre. A Dominação masculina. Rio de Janeiro: Bertrand Brasil, 1999.

BOURDIEU, Pierre. Questões de Sociologia. Rio de Janeiro: Marco Zero, 1983.

BOURDIEU, Pierre; SAINT-MARTIN, Monique de. As categorias do juízo professoral. In: NOGUEIRA, Maria Alice; CATANI, Afrânio (Orgs.). Escritos de Educação. Petrópolis: Vozes, 2012.

CORCUFF, Phillipe. Lo colectivo em el desafío de lo singular: partiendo del habitus. In: LAHIRE, Bernard (Org.). El trabajo sociológico de Pierre Bourdieu: deudas y críticas. Buenos Aires: Siglo XXI Editores Argentina, 2005.

COSTA, António Firmino da. Os desafios da teoria da prática à construção da sociologia. In: PINTO, José Madureira; PEREIRA, Virgílio Borges (Orgs.). Pierre Bourdieu: a teoria da prática e a construção da sociologia em Portugal. Porto: Edições Afrontamento, 2007.

COURY, Amanda Ferreira. Fatos e fotos da enfermeira da Cruz Vermelha Brasileira no enfrentamento da gripe espanhola (1918). 115 f. Dissertação (Mestrado em Enfermagem) Universidade Federal do Rio de Janeiro. Rio de Janeiro, 2010.

DURAND, José Carlos G. Campo da alta costura. In: CATANI, Afrânio Mendes; NOGUEIRA, Maria Alice; HEY, Ana Paula; MEDEIROS, Cristina Carta Cardoso de (Orgs.). Vocabulário Bourdieu. Belo Horizonte: Autêntica, 2017.

GALAK, Eduardo. Mano de obra. El cuerpo em los trabajos etnográficos de Pierre Bourdieu em Argelia. Nómadas. Revista Crítica de Ciencias Sociales y Jurídicas, no 23, 2009. Disponível em: http://revistas.ucm.es/index.php/NOMA/article/view/NOMA0909340081A. Acesso em: 04 ago. 2020.

GARCIA, Clara Zeferino. "De mal com o espelho": Um estudo sobre a (re)configuração de corpos femininos pela cirurgia plástica. 107 f. Dissertação (Mestrado em Ciências Sociais) Universidade Federal de São Paulo. Guarulhos, 2013.

HOBUSS, João. Sobre a disposição em Aristóteles: hexis e diathesis. Dissertatio, Pelotas, n. 31, p.221-233, inverno 2010. Disponível em: http:/www2.ufpel.edu.br/isp/dissertatio/ revistas/31/12.pdf. Acesso em 04 ago. 2020. 
LAHIRE, Bernard. O homem plural - as molas da aç̧ão. Lisboa: Instituto Piaget, 2003. MATOS, Juliana Alves Viana. Práticas corporais: o corpo-cidadão como expressão da promoção da saúde. 214 f. Tese (Doutorado em Enfermagem) - Universidade Federal de Minas Gerais. Belo Horizonte, 2019.

MAUSS, Marcel. As técnicas corporais. In: MAUSS, Marcel. Sociologia e antropologia. São Paulo: EPU/EDUSP, 1984.

MEDEIROS, Cristina Carta Cardoso de. Corpo. In: CATANI, Afrânio Mendes; NOGUEIRA, Maria Alice; HEY, Ana Paula; MEDEIROS, Cristina Carta Cardoso de (Orgs.). Vocabulário Bourdieu. Belo Horizonte: Autêntica, 2017.

MEDEIROS, Cristina Carta Cardoso de. Habitus e corpo social: reflexões sobre o corpo na teoria sociológica de Pierre Bourdieu. Movimento (ESEFID/UFRGS), Porto Alegre, p.281300, jan. 2011. Disponível em: https://seer.ufrgs.br/Movimento/article/view/13430/12953. Acesso em: 04 ago. 2020.

MONTAGNER, Miguel Ângelo. Pierre Bourdieu, o corpo e a saúde: algumas possibilidades teóricas. Ciênc. saúde coletiva, Rio de Janeiro, v. 11, n. 2, p. 15-526, jun. 2006. Disponível em: http://www.scielo.br/pdf/csc/v11n2/30438.pdf. Acesso em: 04 ago. 2020.

NUMMER, Fernanda Valli. "Ser Brigadiano" ou "Trabalhar na Brigada": estilos de vida entre soldados da Brigada Militar. 260 f. Tese (Doutorado em Antropologia Social) Universidade Federal do Rio Grande do Sul. Porto Alegre, 2010.

OLIVEIRA, Jaqueline Maas. Categorias do juízo professoral em conselhos de classe: entre interpretações, julgamentos e implicações. 223 f. Dissertação (Mestrado em Educação) Universidade Federal do Paraná. Curitiba, 2017.

OLIVEIRA, Samuel Gomes de. Ingliding de vogais tônicas como prática estilística no falar porto-alegrense: significados sociais da variação linguística. 225 f. Dissertação (Mestrado em Letras) - Universidade Federal do Rio Grande do Sul. Porto Alegre, 2018.

PETERS, Gabriel. Configurações e reconfigurações na teoria do habitus: um percurso. XIV Congresso Brasileiro de Sociologia, Rio de Janeiro, 2009. Disponível em: http://www.sbsociologia.com.br/portal/index.php?option=com_docman\&task=doc download\&gid=3673\&Itemid=170. Acesso em: 04 ago. 2020.

PETERS, Gabriel. Humano, demasiado mundano: a teoria do habitus em retrospecto. Teoria \& Sociedade, n, 18 (1), p.8-37, 2010.

ROSA, Vitor. As técnicas do corpo em Marcel Mauss e o campo desportivo. Estudos de Sociologia. Araraquara, v. 24, n. 47, p.341-350, jul.-dez. 2019. Disponível em: https:// periodicos.fclar.unesp.br/estudos/article/view/12063/8734. Acesso em: 06 ago. 2020. 


\section{Darbi Masson Suficier, Alexandre Aparecido dos Santos, Mateus Tobias Vieira e Luci Regina Muzzeti}

SAPIRO, Gisèle. Conhecimento praxiológico. In: CATANI, Afrânio Mendes; NOGUEIRA, Maria Alice; HEY, Ana Paula; MEDEIROS, Cristina Carta Cardoso de (Orgs.). Vocabulário Bourdieu. Belo Horizonte: Autêntica Editora, 2017.

SCHNEIDER, Susane. CDF, gente boa! um estudo sobre as categorias do juízo estudantil. 102 f. Dissertação (Mestrado em Educação) - Universidade Regional de Blumenau. Blumenau, 2006.

SETTON, Maria da Graça Jacintho. A teoria do habitus em Pierre Bourdieu: uma leitura contemporânea. Rev. Bras. Educ. Rio de Janeiro, 2002, n. 20, p.60-70. Disponível em: https://www.scielo.br/pdf/rbedu/n20/n20a05. Acesso em: 04 ago. 2020.

SOUZA, Virginia Sposito de. O corpo que dança: a história-social e hexis corporal no balé clássico. 155 f. Dissertação (Mestrado em Artes) - Universidade Estadual de Campinas. Campinas, 2009.

VLASTUIN, Juliana. As "donas da quadra": leitura sociológica das unidades geracionais olímpicas do voleibol feminino no Brasil (1980-2008). 217 f. Tese (Doutorado em Sociologia) - Universidade Federal do Paraná. Curitiba, 2013.

WACQUANT, Loïc. Habitus. In: CATANI, Afrânio Mendes; NOGUEIRA, Maria Alice; HEY, Ana Paula; MEDEIROS, Cristina Carta Cardoso de (Orgs.). Vocabulário Bourdieu. Belo Horizonte: Autêntica, 2017.

WACQUANT, Loïc. Esclarecer o habitus. Educação \& Linguagem, São Bernardo do Campo, ano 10, n. 16, p.63-71, jul./dez. 2007. Disponível em: https://www.metodista.br/ revistas/revistas-ims/index.php/EL/article/view/126/136. Acesso em: 04 ago. 2020.

WACQUANT, Loïc. Seguindo Pierre Bourdieu no campo. Revista de Sociologia e Política, n. 26, jun. 2006. Disponível em: https://revistas.ufpr.br/rsp/article/view/8102/5719. Acesso em: 06 ago. 2020.

WACQUANT, Löic. Habitus. In: BECKERT, Jens; ZAFIROVSKI, Milan (Ed.). International Encyclopedia of Economic Sociology. Londres: Routledge, 2004.

Submetido em: 01/10/2020

Revisões requeridas em: 24/12/2020

Aprovado em: 16/02/2021

Publicado em: 10/09/2021 